\title{
Chloride binding and mobility in sodium carbonate- activated slag pastes and mortars
}

\author{
Xinyuan Ke $\cdot$ Susan A. Bernal $\cdot$ Oday H. Hussein $\cdot$ John L. Provis
}

Received: 31 July 2017 / Accepted: 25 November 2017/Published online: 1 December 2017

(C) The Author(s) 2017. This article is an open access publication

\begin{abstract}
This study evaluates the chloride binding capacity and the migration of chloride in sodium carbonate-activated slag cements and mortars. The effect on chloride mobility and binding of adding a calcined layered double hydroxide (CLDH) to the binder mix was also assessed. Significantly improved durability characteristics can be achieved for sodium carbonate-activated slag mortars by the addition of small fractions of CLDH, as a consequence of a higher degree of reaction, higher chloride binding capacity, and the refined pore structures present in these modified materials, in comparison with alkali-activated cements produced without CLDH. The addition of CLDH enables the production of sodium carbonateactivated slag cements with notably reduced chloride ingress compared to silicate activated slag cements.
\end{abstract}

Keywords Sodium carbonate-activated slag . Layered double hydroxide $\cdot$ Chloride $\cdot$ Durability · Microstructure

X. Ke · S. A. Bernal · O. H. Hussein · J. L. Provis $(\bowtie)$ Department of Materials Science and Engineering, Sir Robert Hadfield Building, The University of Sheffield, Sheffield S1 3JD, UK

e-mail: j.provis@sheffield.ac.uk

\section{Introduction}

Alkali-activated materials have recently gained significant interest as an alternative to Portland cement in many applications [1-3]. Although alkali-activated slag (AAS) cements can be produced with much lower global warming potentials than Portland cement (PC) [4], the use of sodium hydroxide and sodium silicate as activators can bring higher impacts than that of PC in other environmental aspects, including human toxicity, fresh water and marine ecotoxicity [4-6]. In the search for more cost-effective, low-toxicity and environmentally friendly alternatives, the use of nearneutral salts such as sodium carbonate as activators for blast furnace slag has attracted the attention of academia and industry [7-14]. However, the factors controlling the durability and mechanical performance of sodium carbonate-activated slag cement are not yet fully understood. The phase assemblages of AAS cements are mainly controlled by the chemistry of the slags and activators used [7, 15-18], and the microstructures and mechanical properties of AAS cements are also strongly influenced by the type of activator [19-22].

The durability performance of AAS cements, as is the case for materials based on Portland cement, is closely related to the microstructural features of the binder, as well as the chemical reactions that can take place between the binder reaction products and the chemical species present in the service environment. 
Free chloride in a cement pore solution increases the likelihood of corrosion of steel reinforcement, and reduces the durability of concrete structures [23-25]. Measurement of the ionic transport of free chloride in concrete structures is therefore particularly important for service life prediction [26, 27]. The diffusivity of chloride in a cementitious binder is often evaluated by measuring its diffusion and/or migration coefficients.

The interactions of chloride with saturated cementitious materials are governed by physico-chemical phenomena associated with its diffusion through the pore network of hardened concrete, and its tendency to chemically bind to the hydrated phases present. The chemistry of the aqueous environment (e.g. $\mathrm{pH}$, ionic concentration), and the phase assemblage of the cementitious matrix, must be taken into account when studying the chloride binding capacities of AAS cements $[25,28,29]$. The aqueous environment under which the chloride binding capacity is determined in laboratory tests must therefore be comparable to that of the pore solution chemistry of the hardened cement, so that the results are sufficiently representative. Nonetheless, chloride binding capacities of cementitious materials are normally measured in chloride solutions at near-neutral $\mathrm{pH}[29,30]$. This may lead to overestimation of the chloride binding capacity, as a very high initial $\left[\mathrm{Cl}^{-}\right] /\left[\mathrm{OH}^{-}\right]$ratio will favour the binding of chlorides in the solid phases, either through ion exchange or surface adsorption [31]. The use of a highly alkaline chloride-rich simulated pore solution mitigates this effect.

In our previous work, calcined layered double hydroxide (CLDH) was incorporated in sodium carbonate-activated slag paste for improved control of the setting time [14]. CLDH is produced by thermal treatment of a layered double hydroxide mineral such as hydrotalcite, which contains a positively charged layer structure that allows exchange of interlayer anions [32-34]. Recently, CLDH has begun to be used as a 'smart' chemical addition for cementitious materials due to its ion-exchange properties, enhancing performance and durability [14, 35-38]. A recent study also demonstrated the high chloride binding capacity of the different layered double hydroxide (LDH) type phases typically identified in alkaliactivated slag paste [39]. Although LDHs can chemically bind chloride, the potential role of this behaviour in determining the durability of AAS cement is yet to be fully elucidated.
In this study, chemical binding capacities of AAS cements were determined using simulated chloriderich pore solutions. Sodium carbonate-activated slag pastes with 0 and 5 wt $\%$ CLDH addition were studied, and a sodium silicate-activated slag paste was tested as a reference sample. Chloride binding isotherms of all samples in the simulated pore solutions were calculated. The changes in phase assemblage after exposure to chloride-rich simulated pore solutions have been characterised using X-ray diffraction (XRD) and scanning electron microscopy (SEM). Mortar specimens with equivalent compositions to the sodium carbonate and sodium silicate-activated slag pastes were prepared, and tested according to Nordtest NT Build 492 for chloride migration as a function of curing time and mix design. Compressive strengths of mortars at different curing durations, and pore size distributions of selected samples according to mercury intrusion porosimetry (MIP), were also determined. The chloride binding isotherms determined for paste samples can then be used in assessing the factors influencing the migration coefficients measured by accelerated testing of the mortars.

\section{Experimental methods}

\subsection{Materials}

A commercial blast furnace slag was used in this study, with a chemical composition of $41.3 \mathrm{wt} \% \mathrm{CaO}$, $36.0 \mathrm{wt} \% \mathrm{SiO}_{2}, 11.3 \mathrm{wt} \% \mathrm{Al}_{2} \mathrm{O}_{3}$, and $6.5 \mathrm{wt} \% \mathrm{MgO}$; other oxides sum to $2.5 \mathrm{wt} \%$, and loss on ignition at $1000{ }^{\circ} \mathrm{C}$ was $2.0 \mathrm{wt} \%$. This slag had a Blaine fineness of $5056 \pm 22 \mathrm{~cm}^{2} / \mathrm{g}$, and $\mathrm{a} \mathrm{d}_{50}$ of $11.2 \mu \mathrm{m}$ was determined by laser diffraction particle size analysis.

Analytical grade anhydrous sodium silicate powder (Sigma Aldrich, $\mathrm{Na}_{2} \mathrm{SiO}_{3} \geq 99.5 \%$ ), with a $\mathrm{SiO}_{2} /$ $\mathrm{Na}_{2} \mathrm{O}$ molar ratio of 1 , and sodium carbonate powder (Sigma Aldrich, $\mathrm{Na}_{2} \mathrm{CO}_{3} \geq 99.5 \%$ ) were dissolved into water to prepare the activator solutions used in this study. The CLDH used in this study was prepared using the same procedure as in previous studies [14]. CEN Standard Sand, certified in accordance with EN 196-1:2005, was used in all mortar samples. 
2.2 Sample preparation and test methods

\subsubsection{Alkali-activated slag pastes and mortars}

The alkali-activated slag pastes and mortars were prepared according to the mix designs shown in Table 1. Three types of slag pastes were prepared: slag paste produced with sodium carbonate activator without CLDH (denoted P-NC-0) and with CLDH addition (P-NC-1), or sodium silicate activator without CLDH addition (P-NS-0). For mix design purposes the CLDH added to these cements was considered as an additive, and the amount of activator and water added to each unit mass of slag was kept constant. A previous study by the authors [14] demonstrates that CLDH rehydration will consume a fraction of the water added into these cements; however, the changes in the overall water/binder ratio are negligible at $5 \mathrm{wt} \% \mathrm{CLDH}$ addition. The pastes were cured for 28 days before being crushed for chloride binding experiments. Correspondingly, three types of mortars were prepared: sodium carbonate-activated mortars without CLDH (M-NC-0) and with CLDH addition (M-NC-1), and sodium silicate-activated mortars without CLDH addition (M-NS-0). All samples were cured in tightly sealed plastic bags for up to 180 days.

\subsubsection{Chloride binding capacity of AAS pastes}

Four chloride-rich simulated pore solutions (denoted CH-1 to CH-4) were prepared using a mixture of sodium hydroxide (Sigma Aldrich, $\mathrm{NaOH} \geq 98.0 \%$ ) and $\mathrm{NaCl}$ (Sigma Aldrich, $\mathrm{NaCl} \geq 99.5 \%$ ), keeping the total $\mathrm{Na}^{+}$concentration constant at $1.0 \mathrm{~mol} / \mathrm{L}$, but with $\left[\mathrm{Cl}^{-}\right] /\left[\mathrm{OH}^{-}\right]$ratios of $0.1,0.3,1.0$ and 3.0 respectively.

After 28 days of curing, each type of slag paste prepared in this study was crushed with a hammer in sealed plastic bags, and sieved to obtain samples with particle sizes ranging from 0.25 to $0.6 \mathrm{~mm}$. Immediately after crushing, the sieved paste powders were added to chloride-rich solutions with a solid/liquid ratio of $1: 7$ ( $2 \mathrm{~g}$ solids to $14 \mathrm{~g}$ solution) in $15 \mathrm{~mL}$ centrifuge tubes. The tubes were sealed with Parafilm, and stored horizontally at $23 \pm 2{ }^{\circ} \mathrm{C}$ for 2 months to allow them to reach reaction equilibrium, agitated in a roller mixer for $1 \mathrm{~h}$ once per week.

After 2 months, the samples were separated using a centrifuge (Heraeus Biofuge Primo, $4000 \mathrm{rpm}$ for $6 \mathrm{~min})$. The supernatants were collected to enable calculation of chloride binding capacity. The chloride concentration and $\mathrm{pH}$ in the supernatants were measured using a chloride ion-selective electrode (ColeParmer Epoxy solid-state chloride electrode, accuracy $\pm 2 \%$ ) and $\mathrm{pH}$ meter (Oakton Acorn Series). The chloride binding capacity of each slag paste in each aqueous solutions was calculated using Eq. (1).

$Q_{e}=\left(C_{e}-C_{0}\right) \cdot V / m_{\text {input }}$

$Q_{e}$ Chloride binding capacity of solid, mg/g (by dry mass of initial solid). $C_{e}$ Chloride concentration of the supernatant solution, mol/L. $C_{0}$ Initial chloride concentration, mol/L. $V$ Volume of solution, mL. $m_{\text {input }}$ Initial mass of solid, g.

The remaining solids separated from chloride-rich simulated pore solutions were washed using Milli-Q water following the RILEM recommendations for analysis of water soluble chloride content in concrete

Table 1 Mix design of the paste (P) and mortar (M) samples assessed in this study (for each of $100 \mathrm{~g}$ anhydrous slag used)

\begin{tabular}{|c|c|c|c|c|c|c|c|}
\hline Sample ID & Activator type & Mass of slag (g) & Mass of the activator (g) & CLDH (g) & Water $(g)$ & Sand $(\mathrm{g})$ & ${ }^{+} \mathrm{w} / \mathrm{b}$ \\
\hline P-NC-0 & $\mathrm{Na}_{2} \mathrm{CO}_{3}$ & 100 & 8 & 0 & 43.2 & 0 & 0.4 \\
\hline P-NC-1 & & 100 & 8 & 5 & 43.2 & 0 & 0.4 \\
\hline P-NS-0 & $\mathrm{Na}_{2} \mathrm{SiO}_{3}$ & 100 & 7 & 0 & 42.8 & 0 & 0.4 \\
\hline M-NC-0 & $\mathrm{Na}_{2} \mathrm{CO}_{3}$ & 100 & 8 & 0 & 43.2 & 300 & 0.4 \\
\hline M-NC-1 & & 100 & 8 & 5 & 43.2 & 300 & 0.4 \\
\hline M-NS-0 & $\mathrm{Na}_{2} \mathrm{SiO}_{3}$ & 100 & 7 & 0 & 42.8 & 300 & 0.4 \\
\hline
\end{tabular}

${ }^{+}{ }_{\mathrm{w}} / \mathrm{b}=$ water/binder mass ratio (where binder is defined as mass of slag plus activator solids) 
[40], and then dried in a desiccator with controlled relative humidity at $30 \pm 3 \%$ (reached using saturated $\mathrm{CaCl}_{2}$ salt) for 4 days prior to further analysis. Samples were pulverised and analysed via XRD. Additionally, for the pastes exposed to the solution $\mathrm{CH}-3$, part of the paste specimen was embedded in epoxy resin and polished for SEM-EDX analysis, and part was pulverised and analysed by thermogravimetry coupled with mass spectrometry (TG-MS).

\subsubsection{Test methods for AAS mortars}

Mercury intrusion porosity (MIP) was used according to the test procedure recommended by Ma [41]. Samples were sectioned from cubic specimens using a slow saw, with dimensions of no less than $5 \mathrm{~mm}$ each side. About $3 \mathrm{~g}$ of mortar samples were used in each measurement to ensure representative results. The sectioned mortar samples were immersed in isopropanol for $24 \mathrm{~h}$, followed by vacuum drying for 3 days for complete removal of pore water. The MIP tests were then conducted using a Micromeritics Autopore 9600 Mercury Porosimeter, assuming an intrusion contact angle of $130^{\circ}$ and an extrusion contact angle of $104^{\circ}$.

Mortar cubes with dimensions of $50 \times 50 \times 50 \mathrm{~mm}$ were used to test compressive strength, using an automatic compressive testing instrument (Controls Automax5), with a loading speed of $0.25 \mathrm{MPa} / \mathrm{s}$. Triplicate samples were measured per formulation per curing age.

Non-steady state chloride migration coefficients of mortars were determined following the NordTest method NT BUILD 492 [42]. Mortar discs $(\varnothing 100 \times 50 \mathrm{~mm})$ were used, and duplicate samples were prepared per formulation per curing age. Prior to the accelerated chloride migration test, each of the discs was immersed in $1.0 \mathrm{M} \mathrm{NaOH}$ solution under vacuum to obtain pore water-saturated samples; the immersion fluid was selected to have a comparable (but simplified) composition to those predicted by thermodynamic modelling for the cements assessed [43]. At the end of the test, the disc sample was split, and immediately sprayed with $0.1 \mathrm{M}$ silver nitrate $\left(\mathrm{AgNO}_{3}\right)$ to obtain the chloride ingress profile [44]. The non-steady-state migration coefficient was then calculated based on [42], but with a modified value of $0.16 \mathrm{~N}$ selected as the chloride concentration at which the color changes, due to the high alkalinity in the pore solution [45].

\section{Results and discussion}

3.1 Chloride binding capacity of alkali-activated slag pastes

For the specimens assessed, the chloride binding capacity $\left(Q_{e}\right)$ of each slag paste under various aqueous environments was calculated using Eq. (1). Figure 1 shows the chloride binding capacities calculated, as a function of the $\left[\mathrm{Cl}^{-} / \mathrm{OH}^{-}\right]$ratio in the exposure solution. The same trend was identified in all three samples, where the binding increases at higher $\left[\mathrm{Cl}^{-} /\right.$ $\mathrm{OH}^{-}$] ratios. The reduced binding capacity at a low $\left[\mathrm{Cl}^{-} / \mathrm{OH}^{-}\right]$ratio $(\mathrm{CH}-1)$ could be a consequence of the low chloride concentration, and the competition between hydroxyl ions and chloride for potential anion binding sites in the hydrotalcite type phases forming in these cements [39]. Among the three samples assessed, the chloride binding capacity of sodium carbonate-activated slag paste is much lower than that of sodium silicate-activated slag paste, while the chloride binding capacity of the paste containing CLDH (P-NC-1) is higher than that of samples without this addition, independent of the activator used.

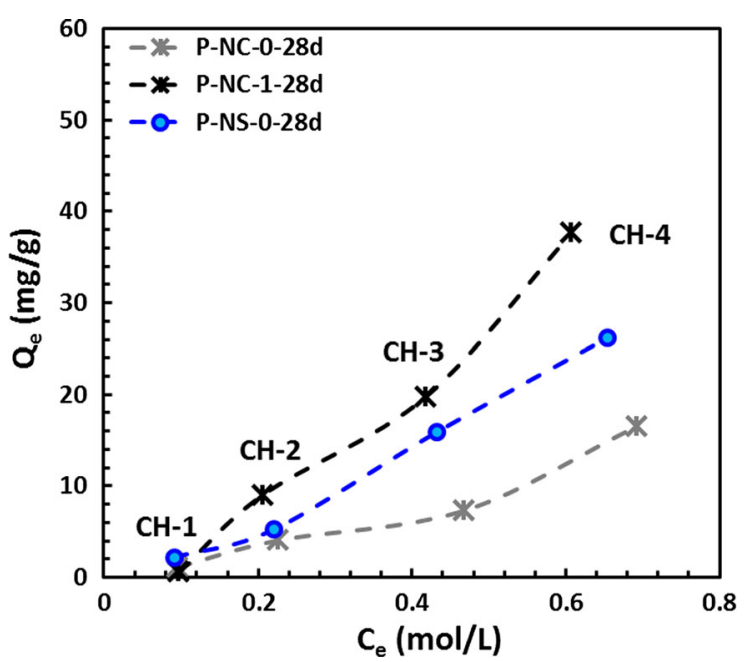

Fig. 1 Chloride binding capacities of 28-day cured alkaliactivated slag pastes determined in chloride-rich simulated pore solutions 
Both hydrotalcite-group phases and carbonateAFm phases (monocarbonate or hemicarbonate) are considered to be effective chloride binding phases $[39,46]$. The main reaction product in AAS cements, which is a sodium-aluminium substituted calcium silicate hydrate $(\mathrm{C}-(\mathrm{N})-\mathrm{A}-\mathrm{S}-\mathrm{H})$ type gel, can also bind chlorides, but with a much lower binding capacity than LDHs [47]. Between the P-NC-0 and P-NS-0 samples, the P-NC-0 sample might contain less binder materials as a result of slower development of reaction comparing with the sodium silicateactivated samples $[9,10]$. Also, the hydrotalcite-like phase in the sodium carbonate-activated samples might contain some carbonate anions [14], leaving less sites available for binding of $\mathrm{Cl}^{-}$[39]. As for CLDH modified samples, the incorporation of CLDH in sodium carbonate-activated slag cements increases the content of hydrotalcite-like phases in the binder. Although the content of AFm phases would decrease [14], the overall content of LDHs (hydrotalcite-like phase + AFm phases) will still be higher than in AAS paste without CLDH modification. Thus, the competition between $\mathrm{CO}_{3}{ }^{2-}$ and $\mathrm{Cl}^{-}$for binding sites in hydrotalcite-like phase would be less significant as the abundance of the hydrotalcite-like phase is high. Also, a higher degree of reaction has been observed in CLDH modified sodium carbonate-activated slag paste, indicating that there are more reaction products available to potentially bind chloride [14]. The increased chloride binding capacity in CLDH modified AAS pastes is therefore a consequence of the higher overall LDH content, compared with nonmodified cements. However, to better understand the changes in the mineralogy of AAS binders after exposure to external chlorides, it is essential to study the solid samples after immersion in chloride-rich simulated pore solutions.

\subsection{Mineralogy of alkali-activated slag pastes after exposure to chloride-rich solutions}

\subsubsection{X-ray diffraction $(X R D)$}

Figure 2 shows the XRD patterns in selected angle ranges to highlight the changes in the reflections of LDH phases upon chloride uptake. In both sodium carbonate-activated samples, with or without CLDH addition, the intensity of the main reflection peak assigned to the AFm-structured monocarbonate phase
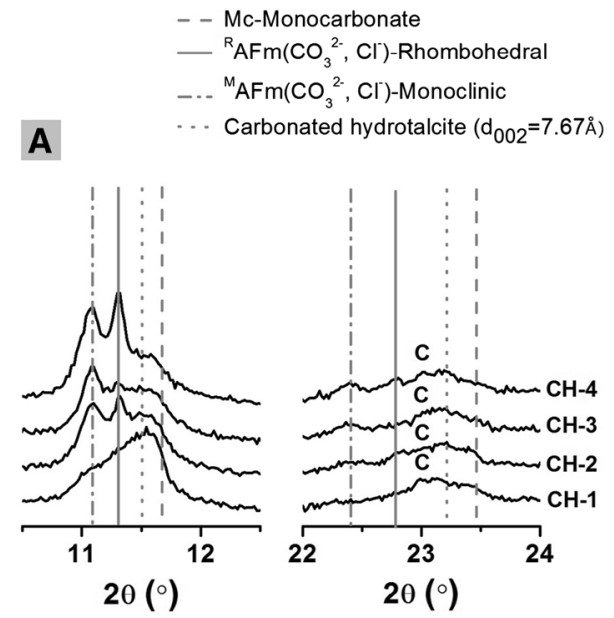

- - Mc-Monocarbonate

- ${ }^{\mathrm{R}} \mathrm{AFm}\left(\mathrm{CO}_{3}{ }^{2-}, \mathrm{Cl}\right)$-Rhombohedral

-.. ${ }^{\mathrm{M}} \mathrm{AFm}\left(\mathrm{CO}_{3}{ }^{2-}, \mathrm{Cl}^{-}\right)$-Monoclinic
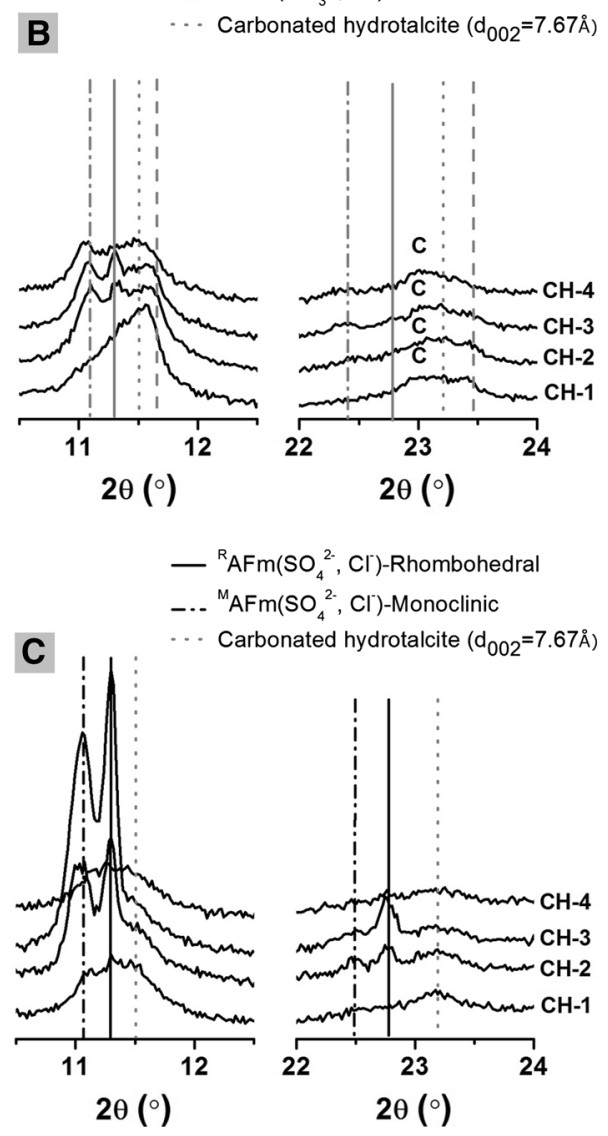

Fig. 2 X-ray diffraction patterns of 28-day cured sodium carbonate-activated slag pastes a without CLDH (P-NC-0), and $\mathbf{b}$ with CLDH (P-NC-1) addition; and $\mathbf{c}$ sodium silicateactivated slag paste (P-NS-0), at chloride binding equilibrium in different simulated pore solutions. $\mathrm{C}$ indicates a reflection due to calcite (PDF\# 00-005-0586) 
decreases as the chloride binding increases. Two polymorphs of Friedel's salt are observed in these specimens, ${ }^{\mathrm{R}} \mathrm{AFm}-\left(\mathrm{CO}_{3}{ }^{2-}, \mathrm{Cl}^{-}\right)$which is close to the structure of rhombohedral hydrocalumite $\left(\mathrm{Ca}_{2}\right.$ $\mathrm{Al}(\mathrm{OH})_{6} \mathrm{Cl} \cdot 2 \mathrm{H}_{2} \mathrm{O}$, powder diffraction file (PDF) \#00035-0105), and ${ }^{\mathrm{M}} \mathrm{AFm}-\left(\mathrm{CO}_{3}{ }^{2-}, \mathrm{Cl}^{-}\right)$which is close to monoclinic hydrocalumite $\left(\mathrm{Ca}_{2} \mathrm{Al}(\mathrm{OH})_{6} \mathrm{Cl} \cdot 2 \mathrm{H}_{2} \mathrm{O}\right.$, PDF\# 00-019-0202), but has a lower basal peak position [48]. The hydrocalumite-type phases formed in sodium carbonate-activated samples were transformed from monocarbonate to Friedel's salt type phases, most likely by replacement of some of the interlayer $\mathrm{CO}_{3}{ }^{2-}$ ions with $\mathrm{Cl}^{-}$ions, as has been proposed by Mesbah et al. [46, 48] The transformation between these two polymorphs of Friedel's salt is described in the literature to be mainly temperature controlled, with the rhombohedral structure preferred at higher temperature (above $35^{\circ} \mathrm{C}$ ) $[46,49,50]$. The differences in interlayer species might affect the transition temperature, however, there has not been any evidence directly correlating the transition between the two polymorphs with changes in interlayer chloride content.

The main reflection peak of a $\mathrm{CO}_{2}$-containing hydrotalcite-like phase with basal spacing $7.67 \AA$ is shown in Fig. 2, as a guideline for identifying hydrotalcite-like phases. In sodium carbonate activated slag pastes ( $\mathrm{P}-\mathrm{NC}-0)$ the interlayer species in the hydrotalcite-like phase can be a mixture of $\mathrm{Cl}^{-}, \mathrm{OH}^{-}$ and $\mathrm{CO}_{3}{ }^{2-}$, considering the chemical composition of the aqueous phase at equilibrium before separation. The intensities of reflections assigned to AFm- $\left(\mathrm{CO}_{3}\right.$, $\mathrm{Cl})$ are much higher in samples without CLDH (Fig. 2b) than in CLDH-containing specimens (Fig. 2a). Less AFm phase was formed in sodium carbonate-activated slag pastes with added CLDH (P$\mathrm{NC}-1)$, as observed in [14], reducing the amount of monocarbonate available to chemically bind chlorides. This emphasises the role of CLDH in increasing the chloride binding capacity of AAS cements, as its inclusion modifies the phase assemblage of these cements, impacting how chloride binding occurs.

In sodium silicate-activated samples (P-NS-0), the poorly crystalline AFm phase (strätlingite-like) transformed into a Friedel's salt-like phase after exposure to a chloride-rich solution. Two polymorphs of chlorocarboaluminate phases were again identified after chloride binding in this specimen. The intensities of the basal peaks assigned to both phases increase as the external $\left[\mathrm{Cl}^{-}\right] /\left[\mathrm{OH}^{-}\right]$ratio rises. This is associated with an increased formation of chloride-bearing AFm phases. However, in specimens exposed to solutions with the highest $\left[\mathrm{Cl}^{-}\right] /\left[\mathrm{OH}^{-}\right]$ratio $(\mathrm{CH}-4)$, the peaks corresponding to chloride bearing AFm phases were not clearly identifiable. As discussed in a previous study [39], any Friedel's salt-like phases formed through the uptake of chlorides by strätlingite will decompose even in alkaline solution ( $\mathrm{pH}$ around 13.6) in the presence of carbonate ions. It is possible that according to such a mechanism, a Friedel's salt-like phase was originally formed in this paste, but decomposed during sample processing or analysis.

\subsubsection{Scanning electron microscopy (SEM-EDX)}

Figure 3 shows the atomic ratios calculated from EDX data for AAS pastes embedded in epoxy resin, after exposure to the chloride-rich solution $\mathrm{CH}-3$. The dashed lines in Fig. 3a, b, showing the ratios $\mathrm{Ca} /$ $\mathrm{Al}=2$ and $\mathrm{Mg} / \mathrm{Al}=2$ respectively, are included to aid identification of the composition regions where AFm and/or hydrotalcite-like phases have been reported [51]. The dashed lines of different $\mathrm{Cl} / \mathrm{Al}$ ratios in Fig. $3 \mathrm{c}$ are given as a guide in evaluating the $\mathrm{Cl}$ content of the reaction products. The maximum $\mathrm{Cl} /$ $\mathrm{Al}$ ratio possible in an AFm phase is around 1.0, as seen in Friedel's salt [52], while the highest $\mathrm{Cl} / \mathrm{Al}$ ratio in a hydrotalcite-like phase measured in simulated pore solutions was around 0.1, as calculated in [39].

The EDX plots for chloride-bearing sodium carbonate-activated samples, shown in Fig. $3 a$, b, are generally similar to those of sodium carbonateactivated samples without exposure to chlorides [14]. The data points in Fig. 3a with $\mathrm{Al} / \mathrm{Si}$ ratios higher than 0.8 and $\mathrm{Ca} / \mathrm{Si}$ ratios around $\mathrm{Ca} / \mathrm{Al}=2$ suggest the formation of crystallised AFm phases in both of the sodium carbonate-activated slag pastes, with and without inclusion of CLDH (P-NC-0 and $\mathrm{P}-\mathrm{NC}-1)$. Between these two samples, the $\mathrm{Mg} / \mathrm{Si}$ atomic ratio in sample $\mathrm{P}-\mathrm{NC}-1$ is higher than that in P-NC-0 (Fig. 3b), consistent with the addition of the $\mathrm{CLDH}$. These results also indicate the existence of the hydrotalcite-like phase intermixed with crystallised AFm phases in sample P-NC-1 [14]. However, the Cl/ $\mathrm{Al}$ ratios in data points collected from regions mainly consisting of hydrotalcite-like and $\mathrm{AFm}(\mathrm{Al} / \mathrm{Si}>0.8)$ phases seem to be similar between sample $\mathrm{P}-\mathrm{NC}-0$ 28d and P-NC-1 (Fig. 3c). It seems that the bulk Cl/Al 

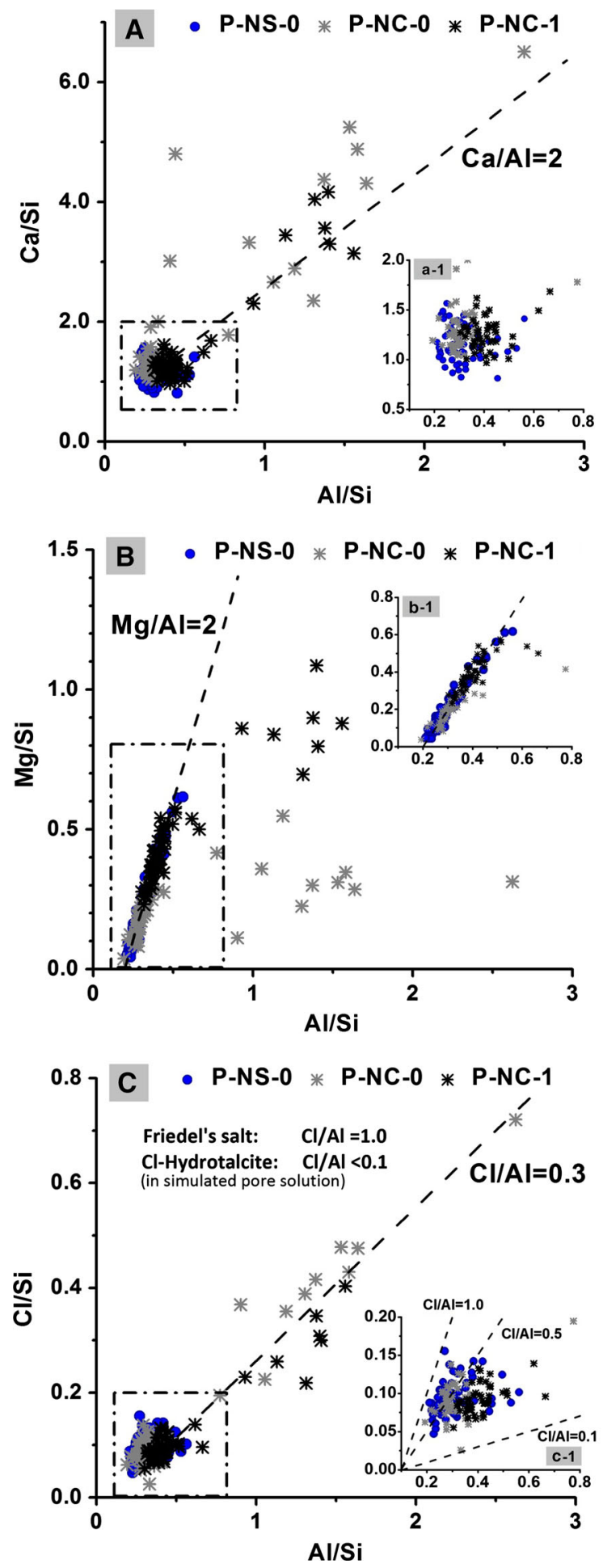

Fig. 3 Atomic ratios calculated from EDX data for 28-day cured alkali-activated slag pastes after exposure to solution $\mathrm{CH}$ 3: $\mathbf{a}$ and (a-1) plotted as $\mathrm{Ca} / \mathrm{Si}$ versus $\mathrm{Al} / \mathrm{Si}, \mathbf{b}$ and (b-1) plotted as $\mathrm{Mg} / \mathrm{Si}$ versus $\mathrm{Al} / \mathrm{Si}$, c and (c-1) plotted as $\mathrm{Cl} / \mathrm{Si}$ versus $\mathrm{Al} / \mathrm{Si}$ ratios in the Friedel's salt-like AFm- $\left(\mathrm{CO}_{3}{ }^{2-}, \mathrm{Cl}^{-}\right)$ phase and the chloride-bearing hydrotalcite-like phase are similar, at around $\mathrm{Cl} / \mathrm{Al}=0.3$.

Compositions corresponding to a discrete AFm phase were not observed in EDX analysis of sample P-NS-0 after exposure to solution $\mathrm{CH}-3$, even though a Friedel's salt-like phase was identified though XRD (Fig. 2). This could possibly be explained by the fact that the AFm phase in sodium silicate-activated slag paste is intimately intermixed with $\mathrm{C}-(\mathrm{N})-\mathrm{A}-\mathrm{S}-\mathrm{H}$ gel $[53,54]$, and therefore it is not distinguishable by SEM-EDX analysis.

The inset plots in Fig. 3 show an expanded view of the data points with $\mathrm{Al} / \mathrm{Si}$ ratios between 0.1 and 0.8 , representing data collected from locations where the $\mathrm{C}-(\mathrm{N})-\mathrm{A}-\mathrm{S}-\mathrm{H}$ type gel is the dominant phase, most likely from the outer product with intermixed hydrotalcite-like and AFm phases [55-57]. From the inset plot in Fig. 3a, the $\mathrm{Ca} / \mathrm{Si}$ ratios in sodium carbonateactivated samples with and without CLDH addition are similar to each other, and slightly higher than in sodium silicate activated slag paste, in accordance with the observations in previous study without chloride exposure [14]. Negligible differences between these three samples were observed from the inset plot in Fig. 3b. Comparing with sample P-NC-0, the overall $\mathrm{Al} / \mathrm{Si}$ ratio is lower in P-NS-0 and higher in P-NC-1, due to an additional supply of Si from the activator (sodium silicate) and $\mathrm{Al}$ from the added CLDH, respectively. In the Fig. $3 c$ inset plot, the sample P-NS-0 showed more EDX points distributed in regions with higher $\mathrm{Cl} / \mathrm{Al}$ ratios, comparing with both sodium carbonate-activated samples. The higher $\mathrm{Cl} / \mathrm{Al}$ ratio in P-NS-0 sample is mostly attributed to the intermixed Friedel's salt-like phase, as observed from XRD patterns (Fig. 2c). Part of the $\mathrm{Al}$ in the bulk chemical composition is present in the $\mathrm{C}-(\mathrm{A})-\mathrm{S}-\mathrm{H}$ type gel, and the highest possible $\mathrm{Al} / \mathrm{Si}$ ratio in the $\mathrm{C}-$ (N)-A-S-H type gel (single phase) is limited to between 0.1 to 0.167 by its cross-linked structure [58, 59], therefore the actual $\mathrm{Cl} / \mathrm{Al}$ ratios in the Friedel's salt-like phase could be close to 1.0 (or mostly within the $\mathrm{Cl} / \mathrm{Al}$ region between 1.0 to 0.5 ). As for the two samples activated using sodium carbonate, it might seem that sample $\mathrm{P}-\mathrm{NC}-0$ has a higher $\mathrm{Cl} / \mathrm{Al}$ ratio than $\mathrm{P}-\mathrm{NC}-1$; however, this could be attributed to a higher $\mathrm{Al}$ content in $\mathrm{P}-\mathrm{NC}-1$ (due to the addition of $\mathrm{CLDH}$ ) rather than a higher $\mathrm{Cl}$ content in P-NC-0. Differences in $\mathrm{Ca} / \mathrm{Si}$ and $\mathrm{Al} / \mathrm{Si}$ ratios of $\mathrm{C}-(\mathrm{N})-\mathrm{A}-\mathrm{S}-$ 
$\mathrm{H}$ type gels would be expected to lead to different chloride binding capacities [47]. However, as shown in Fig. 3a, b, the bulk $\mathrm{Ca} / \mathrm{Si}$ and $\mathrm{Al} / \mathrm{Si}$ ratios of the $\mathrm{C}-$ (N)-A-S-H gels formed in all three samples appeared to be quite similar, although the high intermixing with the LDH phases means that it is difficult to clearly distinguish chlorides interacting specifically with the $\mathrm{C}-(\mathrm{N})-\mathrm{A}-\mathrm{S}-\mathrm{H}$ type phases by EDX.

\subsection{Other factors related to mobility of chlorides in alkali-activated slag mortars}

\subsubsection{Pore structure (MIP)}

For cementitious materials, mercury porosimetry can effectively measure the volume of pores that are directly connected to the sample surface, or connected through large pores [60]. In both paste and mortar samples, the distribution of overall intrudable porosity measured using MIP can reflect the range of pore entry sizes present, which is directly related to permeability and thus ionic transport properties in cementitious materials.

Figure 4 shows the pore size distributions of mortar samples after 180 days of curing as measured by MIP. Sample M-NC-0-180d has the highest overall intrudable porosity, while sample M-NS-0-180d has the lowest. The CLDH-modified sample, M-NC-1-180d, showed much lower intrudable porosity than the unmodified sample M-NC-0-180d, and only slightly higher than that of M-NS-0-180d. Table 2 shows the fraction of gel pores $(<10 \mathrm{~nm})$ [61] within the total intrudable porosities. Based on the results reported in

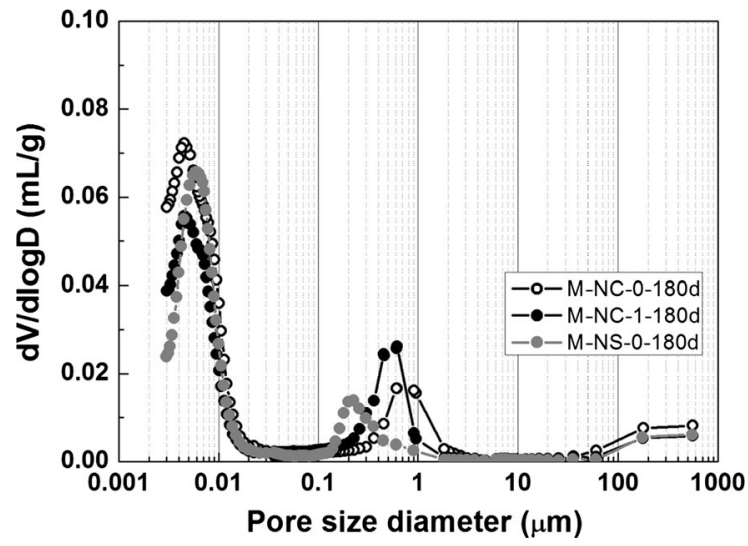

Fig. 4 Differential pore volume distributions of mortar samples NC-0, NC-1, and NS-0 at 180 days of curing
Fig. 4 and Table 2, it is observed that the lower overall intrudable porosity of the CLDH modified sample (MNC-1-180d) than the unmodified sample (M-NC-0$180 \mathrm{~d}$ ) is mainly due to the existence of less gel pores. The absolute value of permeable porosity $(>10 \mathrm{~nm})$ of these two samples is almost the same. Compared with sodium silicate-activated mortars, sodium carbonate-activated mortars exhibit a higher overall intrudable porosity as well as a higher percentage of gel pores, while CLDH-modified sodium carbonateactivated mortar has a lower percentage of gel pores despite its slightly higher overall intrudable porosity.

Previous work showed that CLDH incorporated in sodium carbonate-activated slag paste consumes free water and increases the degree of reaction of slag, as CLDH particles act as nucleation seeding points [14]. Between sample M-NC-0-180d and M-NC-1-180d, the addition of CLDH slightly reduced the overall water/solids ratio, increased the degree of reaction in sodium carbonate-activated slag cement at this given curing time, and at the same time performs partially as a filler [14], all of which factors contribute to the lower critical pore diameter observed in sample M-NC-180d [62]. The more homogeneous microstructure in the paste section (between the unreacted slag grains) in CLDH-modified sodium carbonate-activated slag paste also contributes to the lower overall porosity of mortars produced with these additions.

\subsubsection{Compressive strength}

Figure 5 shows that at each of the curing ages tested here, between the three alkali-activated materials studied, the compressive strength was consistently higher in M-NS-0 than M-NC-1, which was in turn stronger than M-NC-0. The addition of $5 \mathrm{wt} \% \mathrm{CLDH}$ to sodium carbonate-activated slag mortar promoted a significantly increased compressive strength, compared with that obtained for sodium carbonateactivated slag mortars without CLDH, by at least $12 \%$.

The lower strength development of sodium carbonate activated slag cement in comparison with sodium silicate-activated slag cement (under otherwise similar formulation conditions) has been reported in the literature [17, 19, 20,63], and is associated with the differences in phase assemblage and permeability developed in activated slag systems when using different activators. A higher overall volume of connected (intrudable) pores would be expected to 
Table 2 Summary of intrudable porosities, critical pore diameters and apparent bulk densities of mortar samples

\begin{tabular}{llllll}
\hline \multicolumn{5}{c}{ Intrudable porosity $(\%)$} & \\
\cline { 2 - 6 } & Total & Gel pores $(<0.01 \mu \mathrm{m})$ & Permeable pores $(>0.01 \mu \mathrm{m})$ & Critical pore diameter $(\mu \mathrm{m})$ & Bulk density $(\mathrm{g} / \mathrm{mL})$ \\
\hline $\begin{array}{l}\text { M-NC-0- } \\
\begin{array}{l}\text { 180d } \\
\text { M-NC-1- }\end{array}\end{array}$ & 11.94 & 6.98 & 4.96 & 0.763 & 2.2 \\
$\begin{array}{l}\text { 180d } \\
\text { M-NS-0-180d }\end{array}$ & 9.37 & 5.95 & 4.75 & 0.532 & 2.3 \\
\hline
\end{tabular}

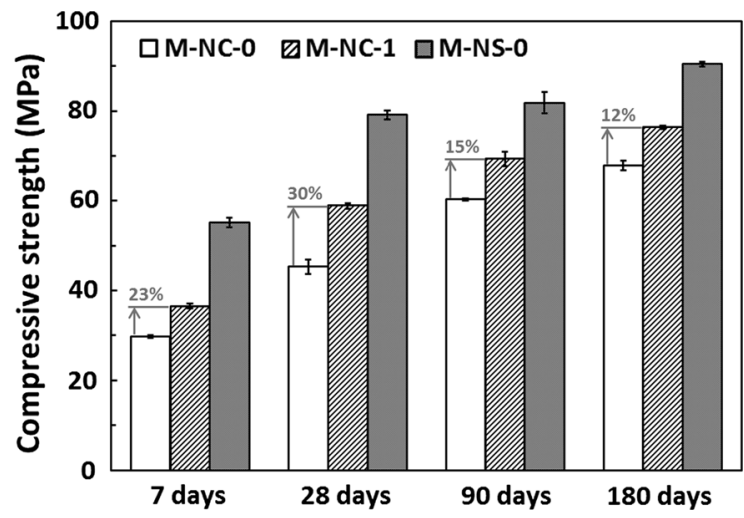

Fig. 5 Compressive strength of M-NC-0, M-NC-1, and M-NS0 mortar cubes at 7,28,90, and 180 days of curing. The results displayed are the mean and standard deviation of three replicates

lead to lower compressive strength [19], and the correlation between these parameters observed here at 180 days (Figs. 4 and 5) is consistent with such a relationship.

Also, it is worthwhile to note from the literature that, when CLDH was blended with calcium sulfoaluminate cement, changes in sample strength were insignificant [35]; when it was blended into Portland cement, decreases in sample strength were observed $[36,37]$. In those cementitious systems the hydrotalcite-like phase is not an intrinsic reaction product; therefore the recrystallised CLDH in those systems performs most likely just as a filler, even though it may also consume water as it rehydrates, and reduce the overall water/binder ratio in those systems. In alkaliactivated slag systems the higher compressive strength identified in CLDH modified samples is a direct consequence of the lower porosity and higher degree of reaction of these binders, demonstrating the unique benefit of CLDH in tailoring sodium carbonateactivated slag cement.

\subsubsection{Non-steady state chloride migration coefficient (NT BUILD 492)}

The NordTest accelerated migration test results for the three mortar mixes assessed are reported in Fig. 6. The lowest and highest possible chloride migration coefficients of these samples have been calculated based on the maximum and minimum points of chloride ingress into the samples tested, to give an illustration of the within-sample variability inherent in this test. This is important because in chloride attack on reinforced concrete, it is the first point of failure (i.e. the maximum depth of ingress) that will determine the service life of an element by inducing corrosion, and so this is more important than simply determining the average depth of ingress over an entire sample.

For sodium carbonate-activated samples, shown in Fig. 6a, b, from 28 to 90 days of curing, both the highest possible chloride migration coefficients and the differences between the average highest and the lowest possible migration coefficients decrease significantly. From 90 to 180 days of curing, changes in the average highest and the lowest possible migration coefficients in these two samples (M-NC-0 and $\mathrm{M}-\mathrm{NC}-1)$ are almost negligible. Comparing M-NC-0 and M-NC-1, the CLDH-modified samples cover a lower range of possible chloride migration coefficient values at all ages. For sodium silicate-activated samples, the differences between the average highest and the lowest possible migration coefficients stayed relatively unchanged, while the highest possible chloride migration coefficients decrease slightly up to 180 days of curing.

The differences between the average highest and the lowest possible migration coefficients represent the range of values that the chloride migration coefficient could possibly fall into, and a smaller 
Fig. 6 Chloride migration coefficient (according to application of NT BUILD 492 with calculation method modified as described in Sect. 2) of a M-NC-0, b M$\mathrm{NC}-1$, and $\mathbf{c} \mathrm{M}-\mathrm{NS}-0$ mortar, after 28,90 , and 180 days of curing. The results displayed are the mean and standard deviation calculated from the highest (upper limit) and lowest (lower limit) chloride ingress depths among 7 readings on each of duplicate specimens
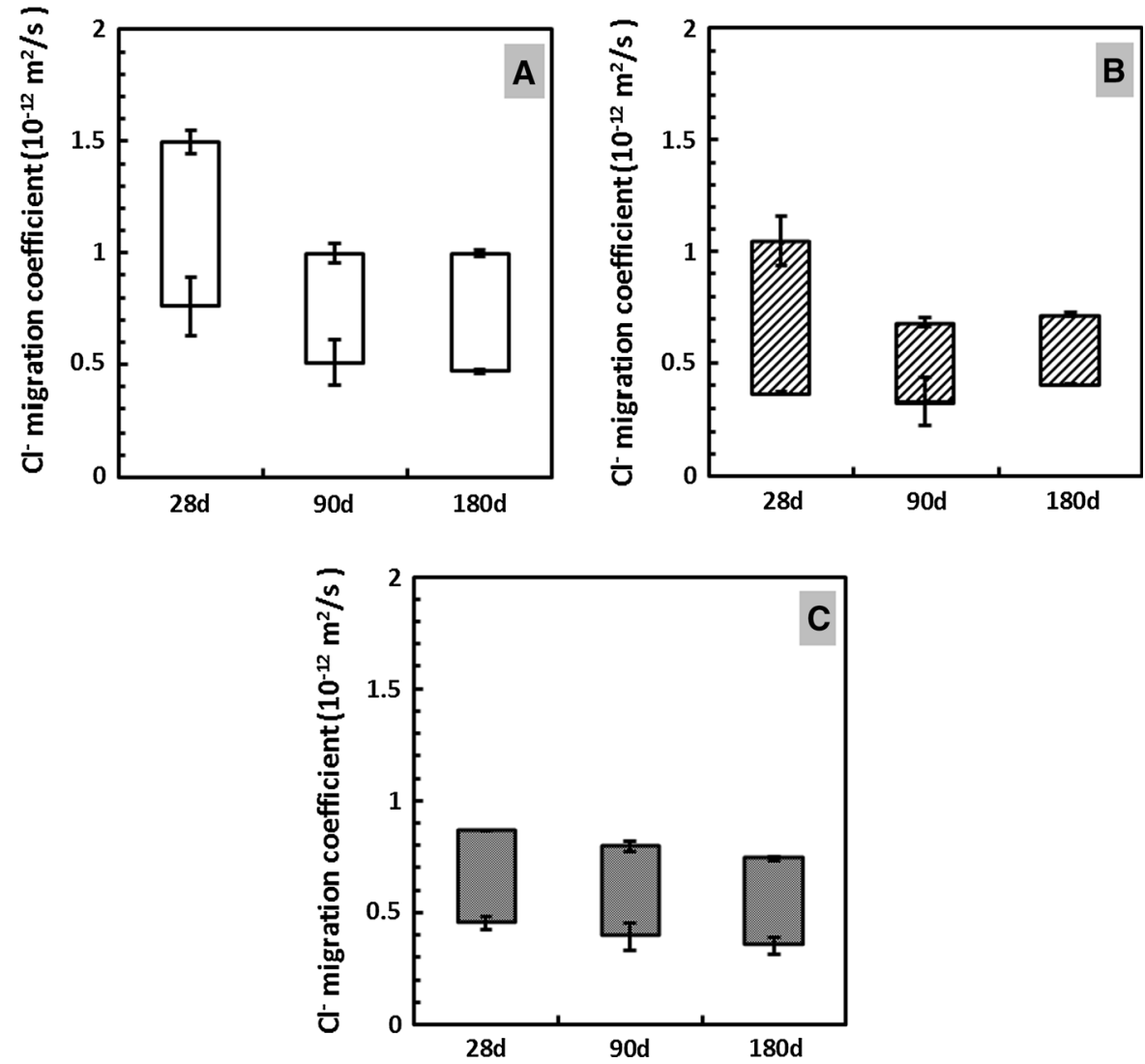

difference indicates a narrower range of withinsample variability. The results in Fig. 6 suggest that sodium carbonate-activated mortars without CLDH (M-NC-0) have significantly higher chloride migration coefficients than sodium silicate activated slag, even at extended curing times. While the CLDH modified sodium carbonate-activated slag mortar (MNC-1) has higher $D_{\text {nssm }}$ values than M-NS-0 up to 90 days of curing, the possible $D_{\text {nssm }}$ ranges are more similar at 180 days of curing.

The non-steady state migration coefficients $D_{\text {nssm }}$ are determined in part by the material microstructure, where a decrease in the critical pore size, as well as total intrudable porosity (as determined by MIP), could result in lower mobility of chlorides through the samples [36, 64]. The mobility of ionic species in gel pores $(<10 \mathrm{~nm})$ is much slower than that in mesopores/macropores, and often considered insignificant for influencing the permeability of gas molecules and ionic species through the samples [61, 65]. A higher percentage of permeable pores could result in higher chloride transport parameters [66]. However, considering the short duration of this accelerated chloride test, the chemical interactions between chlorides and the gel binders would mostly take place locally in permeable pores, as it takes much longer for ionic species to move into the gel pores $[67,68]$.

Considering both the chloride binding capacities (Fig. 1) and MIP results (Table 2) shown in previous sections of this paper, it seems that the higher chloride migration coefficient of sample M-NC-0 compared with M-NS-0, even at 180 days of curing, is most likely caused by a combined effect of higher permeable porosity and lower chloride binding capacity. As for CLDH-modified sodium carbonate-activated mor$\operatorname{tar}$ (M-NC-1-180d), even though it has lower permeable porosity than M-NS-0-180d, its stronger capacity to bind free chloride (compared with M-NS-0-180d) might be the reason that similar chloride coefficients have been observed for these two samples at 180 days of curing. Between these two factors, chloride binding capacity and the permeable porosity of the binders, it seems that the latter might be the dominant factor that controls the chloride migration coefficient under the 
currently tested methods. However, the NordTest method NT 492 involves non-steady state conditions and a short test duration (up to $48 \mathrm{~h}$ ), while the chloride binding capacities were measured after 2 months of reaction, at equilibrium. The effect of chloride binding could therefore be underestimated in such an accelerated test method.

\section{Conclusions}

Sodium carbonate-activated slag paste has a lower chloride binding capacity than with sodium silicateactivated slag paste. However, the incorporation of $5 \mathrm{wt} \% \mathrm{CLDH}$ in the sodium carbonate-activated slag leads to an increase in chloride binding capacity by up to $120 \%$, resulting in higher binding capacities than those of sodium silicate-activated slag pastes under the same testing conditions.

Sodium carbonate-activated samples have higher total intrudable porosity (by MIP), lower compressive strength, and higher chloride migration coefficients, compared with sodium silicate-activated slag materials at equivalent ages. However, with the incorporation of $5 \mathrm{wt} \% \mathrm{CLDH}$ into sodium carbonate-activated slag mortar, the overall intrudable porosity of the sample has been effectively reduced, promoting a more refined pore structure. The effect of CLDH on densifying the microstructure, as well as increasing the chloride binding capacity of sodium carbonate-activated slag cement, results in higher compressive strength and a lower chloride migration coefficient, the values of which are almost comparable to those of sodium silicate-activated slag mortars produced under similar activation conditions. It is evident from the results obtained here that the addition of CLDH plays a critical role in improving the durability performance of sodium carbonate-activated slag cement.

\footnotetext{
Acknowledgements This research was funded by the European Research Council under the European Union's Seventh Framework Programme (FP7/2007-2013)/ERC Grant Agreement \#335928 (GeopolyConc). XK thanks the China Scholarship Council (CSC) for sponsoring her PhD studies. The participation of SAB in this research was partially funded by the UK Engineering and Physical Sciences Research Council through grant EP/M003272/1. This study was performed in part at the MIDAS Facility, at the University of Sheffield, which was established with support from the UK Department of Energy and Climate Change.
}

Open Access This article is distributed under the terms of the Creative Commons Attribution 4.0 International License (http:// creativecommons.org/licenses/by/4.0/), which permits unrestricted use, distribution, and reproduction in any medium, provided you give appropriate credit to the original author(s) and the source, provide a link to the Creative Commons license, and indicate if changes were made.

\section{References}

1. van Deventer JSJ, Duxson P, Provis JL, Brice DG (2010) Chemical research and climate change as drivers in the commercial adoption of alkali activated materials. Waste Biomass Valoriz 1:145-155. https://doi.org/10.1007/ s12649-010-9015-9

2. Provis JL, Brice DG, Buchwald A, Duxson P, Kavalerova E, Krivenko PV, Shi C, van Deventer JSJ, Wiercx JALM (2014) Demonstration projects and applications in building and civil infrastructure. In: Provis JL, van Deventer JSJ (eds) Alkali activated materials: state-of-the-art report of RILEM TC 224-AAM. RILEM. Springer, Dordrecht, pp 309-338. https://doi.org/10.1007/978-94-007-7672-2_11

3. Provis JL (2014) Geopolymers and other alkali activated materials: why, how, and what? Mater Struct 47:11-25. https://doi.org/10.1617/s11527-013-0211-5

4. Habert G, Ouellet-Plamondon C (2016) Recent update on the environmental impact of geopolymers. RILEM Tech Lett 1:7. https://doi.org/10.21809/rilemtechlett.2016.6

5. Provis JL (2014) Green concrete or red herring?-future of alkali-activated materials. Adv Appl Ceram 113(8):472-477. https://doi.org/10.1179/1743676114Y.0000000177

6. Habert G, d'Espinose de Lacaillerie JB, Roussel N (2011) An environmental evaluation of geopolymer based concrete production: reviewing current research trends. J Clean Prod 19(11):1229-1238. https://doi.org/10.1016/j.jclepro.2011. 03.012

7. Provis JL, Bernal SA (2014) Geopolymers and related alkaliactivated materials. Annu Rev Mater Res 44:299-327. https://doi.org/10.1146/annurev-matsci-070813-113515

8. Bai Y, Collier NC, Milestone NB, Yang CH (2011) The potential for using slags activated with near neutral salts as immobilisation matrices for nuclear wastes containing reactive metals. J Nucl Mater 413(3):183-192. https://doi. org/10.1016/j.jnucmat.2011.04.011

9. Bernal SA, Provis JL, Myers RJ, San Nicolas R, van Deventer JSJ (2014) Role of carbonates in the chemical evolution of sodium carbonate-activated slag binders. Mater Struct 48(3):517-529. https://doi.org/10.1617/s11527-0140412-6

10. Bernal SA, San Nicolas R, van Deventer JSJ, Provis JL (2015) Alkali-activated slag cements produced with a blended sodium carbonate/silicate activator. Adv Cem Res 28(4):262-273. https://doi.org/10.1680/jadcr.15.00013

11. Shi C, Roy D, Krivenko P (2006) Alkali-activated cements and concretes. Taylor \& Francis, Abingdon

12. Fernández-Jiménez A, Puertas F (2001) Setting of alkaliactivated slag cement. Influence of activator nature. Adv 
Cem Res 13(3):115-121. https://doi.org/10.1680/adcr. 2001.13.3.115

13. Escalante-García JI, Fuentes AF, Gorokhovsky A, FraireLuna PE, Mendoza-Suarez G (2003) Hydration products and reactivity of blast-furnace slag activated by various alkalis. J Am Ceram Soc 86(12):2148-2153. https://doi.org/ 10.1111/j.1151-2916.2003.tb03623.x

14. Ke X, Bernal SA, Provis JL (2016) Controlling the reaction kinetics of sodium carbonate-activated slag cements using calcined layered double hydroxides. Cem Concr Res 81:24-37. https://doi.org/10.1016/j.cemconres.2015.11.012

15. Ben Haha M, Lothenbach B, Le Saout G, Winnefeld F (2011) Influence of slag chemistry on the hydration of alkali-activated blast-furnace slag-part I: effect of $\mathrm{MgO}$. Cem Concr Res 41(9):955-963. https://doi.org/10.1016/j. cemconres.2011.05.002

16. Winnefeld F, Ben Haha M, Le Saout G, Costoya M, Ko S-C, Lothenbach B (2015) Influence of slag composition on the hydration of alkali-activated slags. J Sustain Cem Based Mater 4:85-100. https://doi.org/10.1080/21650373.2014. 955550

17. Wang S-D, Scrivener KL, Pratt PL (1994) Factors affecting the strength of alkali-activated slag. Cem Concr Res 24(6):1033-1043. https://doi.org/10.1016/0008-8846(94) 90026-4

18. Song S, Sohn D, Jennings HM, Mason TO (2000) Hydration of alkali-activated ground granulated blast furnace slag. J Mater Sci 35(1):249-257. https://doi.org/10.1023/A: 1004742027117

19. Shi C (1996) Strength, pore structure and permeability of alkaliactivated slag mortars. Cem Concr Res 26(12):1789-1799. https://doi.org/10.1016/S0008-8846(96)00174-3

20. Fernández-Jiménez A, Palomo JG, Puertas F (1999) Alkaliactivated slag mortars: mechanical strength behaviour. Cem Concr Res 29(8):1313-1321. https://doi.org/10.1016/ S0008-8846(99)00154-4

21. Jin F, Al-Tabbaa A (2015) Strength and drying shrinkage of slag paste activated by sodium carbonate and reactive $\mathrm{MgO}$. Constr Build Mater 81:58-65. https://doi.org/10.1016/j. conbuildmat.2015.01.082

22. Fernández-Jiménez A, Puertas F (2003) Effect of activator mix on the hydration and strength behaviour of alkali-activated slag cements. Adv Cem Res 15:129-136. https://doi. org/10.1680/adcr.2003.15.3.129

23. Tuutti K (1982) Corrosion of steel in concrete. Building Materials KTH, Kungliga Tekniska Högskolan i Stockholm, CBI Forskning 82:4

24. Ann KY, Song H-W (2007) Chloride threshold level for corrosion of steel in concrete. Corros Sci 49(11):4113-4133. https://doi.org/10.1016/j.corsci.2007.05.007

25. Yuan Q, Shi C, De Schutter G, Audenaert K, Deng D (2009) Chloride binding of cement-based materials subjected to external chloride environment - a review. Constr Build Mater 23(1):1-13. https://doi.org/10.1016/j.conbuildmat. 2008.02.004

26. Andrade C, Prieto M, Tanner P, Tavares F, d'Andrea R (2013) Testing and modelling chloride penetration into concrete. Constr Build Mater 39:9-18. https://doi.org/10. 1016/j.conbuildmat.2012.08.012

27. Ismail I, Bernal SA, Provis JL, San Nicolas R, Brice DG, Kilcullen AR, Hamdan S, van Deventer JSJ (2013)
Influence of fly ash on the water and chloride permeability of alkali-activated slag mortars and concretes. Constr Build Mater 48:1187-1201. https://doi.org/10.1016/j.conbuildmat. 2013.07.106

28. Florea MVA, Brouwers HJH (2014) Modelling of chloride binding related to hydration products in slag-blended cements. Constr Build Mater 64:421-430. https://doi.org/ 10.1016/j.conbuildmat.2014.04.038

29. Dhir RK, El-Mohr MAK, Dyer TD (1996) Chloride binding in GGBS concrete. Cem Concr Res 26(12):1767-1773. https://doi.org/10.1016/S0008-8846(96)00180-9

30. Thomas MDA, Hooton RD, Scott A, Zibara H (2012) The effect of supplementary cementitious materials on chloride binding in hardened cement paste. Cem Concr Res 42(1):1-7. https://doi.org/10.1016/j.cemconres.2011.01.001

31. Trefalt G, Behrens SH, Borkovec M (2016) Charge regulation in the electrical double layer: ion adsorption and surface interactions. Langmuir 32(2):380-400. https://doi. org/10.1021/acs.langmuir.5b03611

32. Morimoto K, Anraku S, Hoshino J, Yoneda T, Sato T (2012) Surface complexation reactions of inorganic anions on hydrotalcite-like compounds. J Colloid Interface Sci 384(1):99-104. https://doi.org/10.1016/j.jcis.2012.06.072

33. Lv L, He J, Wei M, Evans DG, Duan X (2006) Uptake of chloride ion from aqueous solution by calcined layered double hydroxides: equilibrium and kinetic studies. Water Res 40(4):735-743. https://doi.org/10.1016/j.watres.2005. 11.043

34. Miyata S (1983) Anion-exchange properties of hydrotalcitelike compounds. Clays Clay Miner 31(4):305-311. https:// doi.org/10.1346/CCMN.1983.0310409

35. Duan P, Chen W, Ma J, Shui Z (2013) Influence of layered double hydroxides on microstructure and carbonation resistance of sulphoaluminate cement concrete. Constr Build Mater 48:601-609. https://doi.org/10.1016/j. conbuildmat.2013.07.049

36. Yang Z, Fischer H, Polder R (2015) Laboratory investigation of the influence of two types of modified hydrotalcites on chloride ingress into cement mortar. Cem Concr Compos 58:105-113. https://doi.org/10.1016/j.cemconcomp.2014. 12.016

37. Yoon S, Moon J, Bae S, Duan X, Giannelis EP, Monteiro PM (2014) Chloride adsorption by calcined layered double hydroxides in hardened Portland cement paste. Mater Chem Phys 145(3):376-386. https://doi.org/10.1016/j.matchemphys. 2014.02.026

38. Kayali O, Khan MSH, Sharfuddin Ahmed M (2012) The role of hydrotalcite in chloride binding and corrosion protection in concretes with ground granulated blast furnace slag. Cem Concr Compos 34(8):936-945. https://doi.org/ 10.1016/j.cemconcomp.2012.04.009

39. Ke X, Bernal SA, Provis JL (2017) Uptake of chloride and carbonate by $\mathrm{Mg}-\mathrm{Al}$ and $\mathrm{Ca}-\mathrm{Al}$ layered double hydroxides in simulated pore solutions of alkali-activated slag cement. Cem Concr Res 100:1-13. https://doi.org/10.1016/j. cemconres.2017.05.015

40. RILEM TC 178-TMC (2002) Recommendations of RILEM TC 178-TMC: testing and modelling chloride penetration in concrete analysis of water soluble chloride content in concrete. Mater Struct 35(9):586-588. https://doi.org/10.1007/ BF02483129 
41. Ma H (2014) Mercury intrusion porosimetry in concrete technology: tips in measurement, pore structure parameter acquisition and application. J Porous Mater 21(2):207-215. https://doi.org/10.1007/s10934-013-9765-4

42. NordTest Method NT BUILD 492 (1999) Concrete, mortar and cement-based repair materials: chloride migration coefficient from non-steady-state migration experiments. NordTest, Espoo

43. Myers RJ, Lothenbach B, Bernal SA, Provis JL (2015) Thermodynamic modelling of alkali-activated slag cements. Appl Geochem 61:233-247. https://doi.org/10. 1016/j.apgeochem.2015.06.006

44. He F, Shi C, Yuan Q, Chen C, Zheng K (2012) $\mathrm{AgNO}_{3}-$ based colorimetric methods for measurement of chloride penetration in concrete. Constr Build Mater 26(1):1-8. https://doi.org/10.1016/j.conbuildmat.2011.06.003

45. Yuan Q, Shi C, He F, De Schutter G, Audenaert K, Zheng K (2008) Effect of hydroxyl ions on chloride penetration depth measurement using the colorimetric method. Cem Concr Res 38(10):1177-1180. https://doi.org/10.1016/j.cemconres. 2008.04.003

46. Mesbah A, Cau-dit-Coumes C, Frizon F, Leroux F, Ravaux J, Renaudin $\mathrm{G}$ (2011) A new investigation of the $\mathrm{Cl}^{-}-\mathrm{CO}_{3}{ }^{2-}$ substitution in AFm phases. J Am Ceram Soc 94(6):19011910. https://doi.org/10.1111/j.1551-2916.2010.04305.x

47. Ke X, Bernal SA, Provis JL (2017) Chloride binding capacity of synthetic C-(A)-S-H type gels in alkali-activated slag simulated pore solutions. In: Proceedings of the 1st international conference on construction materials for sustainable future, Zadar, Croatia

48. Mesbah A, Rapin J-P, François M, Cau-dit-Coumes C, Frizon F, Leroux F, Renaudin G (2011) Crystal structures and phase transition of cementitious bi-anionic $\mathrm{AFm}-\left(\mathrm{Cl}^{-}\right.$, $\mathrm{CO}_{3}{ }^{2-}$ ) compounds. J Am Ceram Soc 94(1):261-268. https://doi.org/10.1111/j.1551-2916.2010.04050.x

49. Andersen MD, Jakobsen HJ, Skibsted J (2002) Characterization of the $\alpha-\beta$ phase transition in Friedels salt $\left(\mathrm{Ca}_{2}\right.$ $\left.\mathrm{Al}(\mathrm{OH})_{6} \mathrm{Cl} \cdot 2 \mathrm{H}_{2} \mathrm{O}\right)$ by variable-temperature ${ }^{27} \mathrm{Al}$ MAS NMR spectroscopy. J Phys Chem A 106:6676-6682. https://doi. org/10.1021/jp014573p

50. Renaudin G, Kubel F, Rivera JP, Francois M (1999) Structural phase transition and high temperature phase structure of Friedels salt, $3 \mathrm{CaO} \cdot \mathrm{Al}_{2} \mathrm{O}_{3} \cdot \mathrm{CaCl}_{2} \cdot 10 \mathrm{H}_{2} \mathrm{O}$. Cem Concr Res 29(12):1937-1942. https://doi.org/10.1016/ S0008-8846(99)00199-4

51. Matschei T, Lothenbach B, Glasser FP (2007) The AFm phase in Portland cement. Cem Concr Res 37(2):118-130. https://doi.org/10.1016/j.cemconres.2006.10.010

52. Birnin-Yauri UA, Glasser FP (1998) Friedel's salt, $\mathrm{Ca}_{2}$ $\mathrm{Al}(\mathrm{OH})_{6}(\mathrm{Cl}, \mathrm{OH}) \cdot 2 \mathrm{H}_{2} \mathrm{O}$ : its solid solutions and their role in chloride binding. Cem Concr Res 28(12):1713-1723. https://doi.org/10.1016/S0008-8846(98)00162-8

53. Bernal SA, Provis JL, Walkley B, San Nicolas R, Gehman JD, Brice DG, Kilcullen AR, Duxson P, van Deventer JSJ (2013) Gel nanostructure in alkali-activated binders based on slag and fly ash, and effects of accelerated carbonation. Cem Concr Res 53:127-144. https://doi.org/10.1016/j. cemconres.2013.06.007

54. Wang S-D, Scrivener KL (1995) Hydration products of alkali activated slag cement. Cem Concr Res 25(3):561-571. https://doi.org/10.1016/0008-8846(95)00045-E
55. San Nicolas R, Bernal SA, Mejía de Gutiérrez R, van Deventer JSJ, Provis JL (2014) Distinctive microstructural features of aged sodium silicate-activated slag concretes. Cem Concr Res 65:41-51. https://doi.org/10.1016/j. cemconres.2014.07.008

56. Famy C, Scrivener KL, Crumbie AK (2002) What causes differences of $\mathrm{C}-\mathrm{S}-\mathrm{H}$ gel grey levels in backscattered electron images? Cem Concr Res 32(9):1465-1471. https:// doi.org/10.1016/S0008-8846(02)00808-6

57. Bernal SA, San Nicolas R, Myers RJ, Mejía de Gutiérrez R, Puertas F, van Deventer JSJ, Provis JL (2014) MgO content of slag controls phase evolution and structural changes induced by accelerated carbonation in alkali-activated binders. Cem Concr Res 57:33-43. https://doi.org/10.1016/j. cemconres.2013.12.003

58. Myers RJ, Bernal SA, San Nicolas R, Provis JL (2013) Generalized structural description of calcium-sodium aluminosilicate hydrate gels: the cross-linked substituted tobermorite model. Langmuir 29(17):5294-5306. https:// doi.org/10.1021/la4000473

59. L'Hôpital E, Lothenbach B, Le Saout G, Kulik D, Scrivener $\mathrm{K}$ (2015) Incorporation of aluminium in calcium-silicatehydrates. Cem Concr Res 75:91-103. https://doi.org/10. 1016/j.cemconres.2015.04.007

60. Cook RA, Hover KC (1999) Mercury porosimetry of hardened cement pastes. Cem Concr Res 29(6):933-943. https://doi.org/10.1016/S0008-8846(99)00083-6

61. Cui L, Cahyadi JH (2001) Permeability and pore structure of OPC paste. Cem Concr Res 31(2):277-282. https://doi.org/ 10.1016/S0008-8846(00)00474-9

62. Atahan HN, Oktar ON, Taşdemir MA (2009) Effects of water-cement ratio and curing time on the critical pore width of hardened cement paste. Constr Build Mater 23(3):11961200. https://doi.org/10.1016/j.conbuildmat.2008.08.011

63. Duran Atiş C, Bilim C, Çelik Ö, Karahan O (2009) Influence of activator on the strength and drying shrinkage of alkaliactivated slag mortar. Constr Build Mater 23(1):548-555. https://doi.org/10.1016/j.conbuildmat.2007.10.011

64. Ravikumar D, Neithalath N (2013) Electrically induced chloride ion transport in alkali activated slag concretes and the influence of microstructure. Cem Concr Res 47:31-42. https://doi.org/10.1016/j.cemconres.2013.01.007

65. Halamickova P, Detwiler RJ, Bentz DP, Garboczi EJ (1995) Water permeability and chloride ion diffusion in Portland cement mortars: relationship to sand content and critical pore diameter. Cem Concr Res 25(4):790-802. https://doi. org/10.1016/0008-8846(95)00069-O

66. Neithalath N, Jain J (2010) Relating rapid chloride transport parameters of concretes to microstructural features extracted from electrical impedance. Cem Concr Res 40(7):10411051. https://doi.org/10.1016/j.cemconres.2010.02.016

67. He F, Shi C, Hu X, Wang R, Shi Z, Li Q, Li P, An X (2016) Calculation of chloride ion concentration in expressed pore solution of cement-based materials exposed to a chloride salt solution. Cem Concr Res 89:168-176. https://doi.org/ 10.1016/j.cemconres.2016.08.006

68. Friedmann H, Amiri O, Aït-Mokhtar A (2008) Physical modeling of the electrical double layer effects on multispecies ions transport in cement-based materials. Cem Concr Res 38(12):1394-1400. https://doi.org/10.1016/j. cemconres.2008.06.003 